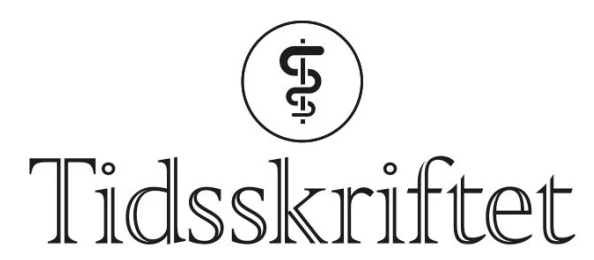

DEN NORSKE LEGEFORENING

\title{
Hjerneslag som eget fagfelt
}

KRONIKK

\section{LARS THOMASSEN}

lathom2@online.no

Lars Thomassen er spesialist i nevrologi, professor emeritus ved Universitetet i Bergen, tidligere overlege og leder av slagenheten ved Nevrologisk avdeling, nå forsker ved Nevroklinikken, Haukeland universitetssjukehus.

Forfatteren har fylt ut ICMJE-skjemaet og oppgir ingen interessekonflikter.

\section{MARTIN KURZ}

Martin Kurz er spesialist i nevrologi, professor II ved Klinisk institutt 1, Universitetet i Bergen, seksjonsoverlege i Nevrosenteret, Stavanger universitetssjukehus og leder i Norsk hjerneslagforening.

Forfatteren har fylt ut ICMJE-skjemaet og oppgir ingen interessekonflikter.

\section{OLE MORTEN RØNNING}

Ole Morten Rønning er spesialist i nevrologi, professor II ved Klinikk for indremedisin og laboratoriefag, Institutt for klinisk medisin, Universitetet i Oslo, og seksjonsoverlege ved Seksjon for akutt hjerneslag, Nevroklinikken, Akershus universitetssykehus. Han er medlem av styret i Norsk hjerneslagforening.

Forfatteren har fylt ut ICMJE-skjemaet og oppgir ingen interessekonflikter.

Vaskulær nevrologi er annerledes enn generell nevrologi og fremstår i praksis som et eget akuttmedisinsk fagfelt. Bør det innføres formalisert kompetanse og en definert ramme for utdanning i vaskulær nevrologi? 


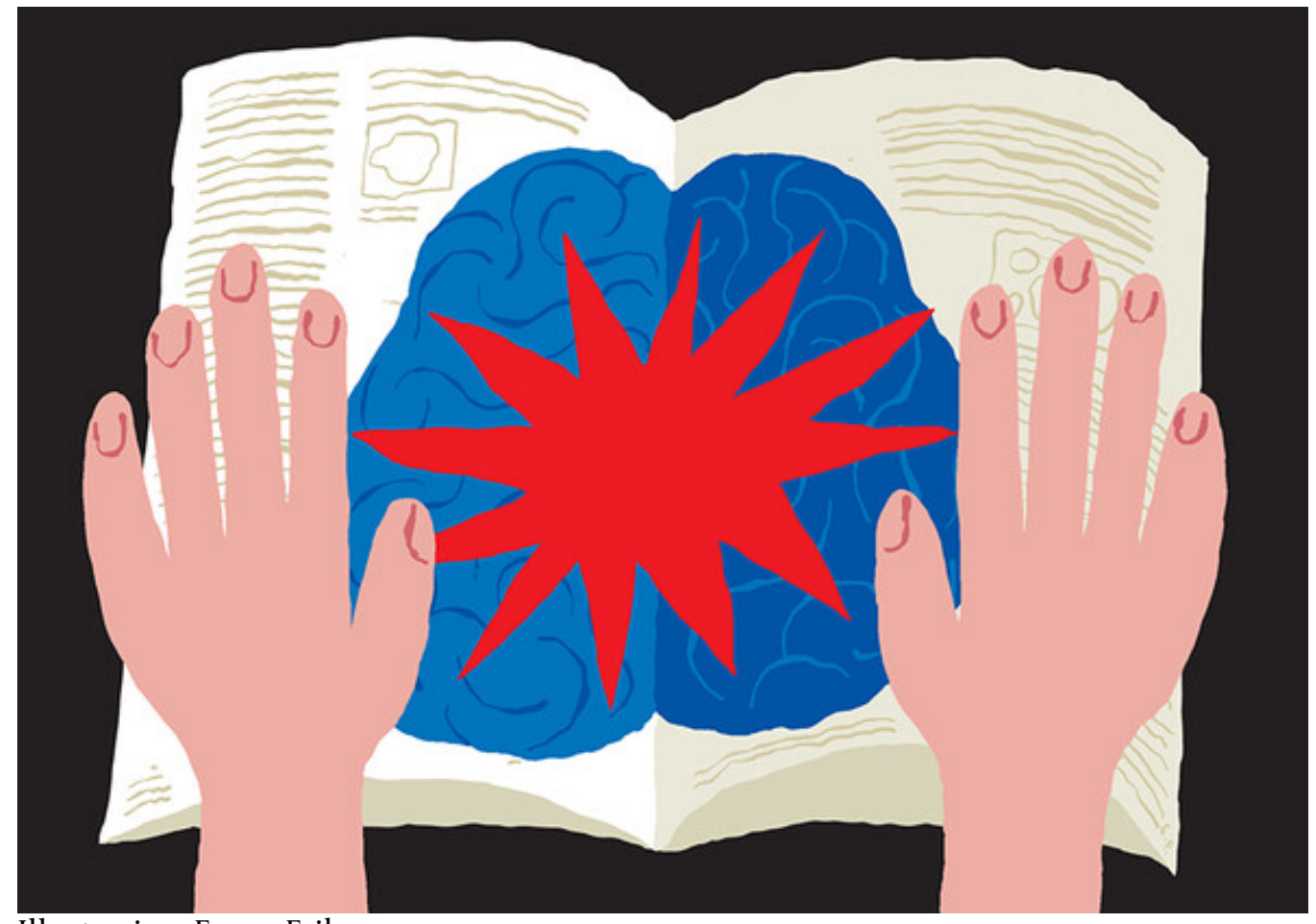

Illustrasjon: Espen Friberg

Årlig rammer hjerneslag om lag 10 ooo personer, og rundt 6o \% av disse behandles ved nevrologiske avdelinger $(\underline{1}, \underline{2})$. Hjerneslag er en av våre store folkesykdommer, på linje med hjerte- og kreftsykdommer. Men i motsetning til disse foreligger ingen definert faglig ramme for utdanning og spesifikke kompetansekrav for hjerneslagsykdommene. Nevrologien hadde i mange år rehabilitering av pasienter med følgetilstander etter hjerneslag som hovedoppgave innenfor slagmedisinen (3). Parallelt med innføring av intravenøs trombolytisk behandling, intraarteriell trombektomi og avansert bildediagnostikk i utredning og behandling av akutt hjerneinfarkt, har den generelle nevrologien endret seg til å omfatte også akutt vaskulær nevrologi.

\section{Akuttkjeden}

Tid er avgjørende ved behandling av akutt hjerneslag, og slagpasienten må tilbys en effektiv behandlingskjede (4-ㅡㅡ). Pasienten innlegges med spørsmål om hjerneslag. Det er mange prehospitale differensialdiagnoser å utelukke, hjerneslagimitatorer (stroke mimics) må avklares, og pasienten må sikres rask ambulansetransport til riktig sted (7.).

\section{"Tid er avgjørende ved behandling av akutt hjerneslag, og slagpasienten må tilbys en effektiv behandlingskjede»}

I akuttmottaket må ikke bare nevrologiske differensialdiagnoser vurderes, men også nevrovaskulære, kardiovaskulære og indremedisinske diagnoser. Akutt radiologisk bildediagnostikk understøtter vurderingen. Den akutte behandlingskjeden ved innleggelse i nevrologisk avdeling forutsetter effektivt samarbeid mellom nevrolog og prehospital tjeneste, akuttmottak, radiologi og anestesiologi. Det er nødvendig med vaskulær nevrologisk kompetanse i alle ledd $(\underline{8-12})$. Generell nevrologi møter her en utfordring. Vaskulær nevrologi er vesensforskjellig fra generell nevrologi. I generell nevrologi møter man akutte krisesituasjoner i begrenset omfang, i vaskulær nevrologi er akuttsituasjonen pasientens utgangspunkt. Er generell nevrologi det riktige svaret på akuttkjedens behov?

\section{Behandlingen}


Behandlingsalternativer ved akutt hjerneinfarkt er trombolyse og trombektomi. Behandlingsindikasjonen baseres på informasjon om tidligere nevrologisk funksjon, akutte nevrologiske utfall, tidspunkt i behandlingsvinduet, blodproppens lokalisasjon, kollateralsirkulasjon, perfusjon i hjernevevet og grad av allerede inntrådt celledød. Mulig behandlingseffekt (arteriell rekanalisering og klinisk bedring) må veies opp mot mulige bivirkninger (hjerneblødning og død). Adekvat behandling forutsetter derfor solid kunnskap om hjernens blodsirkulasjon og hjerneinfarktets patofysiologi, supplert med forståelse av avansert nevroradiologisk diagnostikk. Er spesialistutdanningens krav om ett todagerskurs i hjernens blodsirkulasjon tilstrekkelig som grunnlag for krevende behandlingsavgjørelser?

\section{Slagovervåkingen}

Når pasienten ankommer slagovervåkingen, er den cerebrale sirkulasjonen ustabil. For å være i forkant av en klinisk forverring må generelle parametere som hjertefunksjon, blodtrykk, lungefunksjon, oksygenmetning, temperatur, blodsukker og væskebalanse overvåkes tett, i tillegg til at spesielle parametere ved cerebral sirkulasjon og hemodynamikk monitoreres med ultralydundersøkelser $(13,14)$.

«Er spesialistutdanningens krav om ett todagerskurs i hjernens

blodsirkulasjon tilstrekkelig som grunnlag for krevende

behandlingsavgjørelser?»

Pasienter med hjerneblødninger eller malignt hjerneødem trenger spesiell overvåking, eventuelt nevrointensiv behandling. Ved gitt indikasjon må nevrokirurg involveres. I generell nevrologi overlates elektrofysiologisk overvåking av hjernen (EEG) til spesialister i klinisk nevrofysiologi, i vaskulær nevrologi må sirkulasjonsfysiologisk overvåking (ultralyd) utføres av vaskulært skolerte nevrologer (15). I generell nevrologi er vurdering av hjertefunksjon, blodtrykk, lungefunksjon, oksygenmetning, blodsukker og væskebalanse ikke sentrale oppgaver, i vaskulær nevrologi er dette daglig rutine. Bør generell nevrologi ta seg av komplisert overvåkingsmedisin uten spesialutdanning?

\section{Nevrovaskulært laboratorium}

Gjentatte radiologiske undersøkelser som CT eller MR er ikke egnet til overvåking. Transkranial ultralyd kan derimot benyttes ved sykesengen under pågående generell overvåking, kan gjentas hyppig, er uten særlig belastning for pasientene og kan gi fortløpende informasjon om endringer i hjernens sirkulasjon (15). Klinisk nevrosonologi er imidlertid teoretisk og praktisk krevende og stiller store faglige krav til den som utfører undersøkelsene $(\underline{16}, \underline{17}$.$) . Allikevel omfatter spesialistutdanningen i generell nevrologi ingen$ anbefalinger om utdanning i klinisk nevrosonologi. Er dette tilfredsstillende kompetanseoppbygging i et spesialisert felt?

\section{Slagenheten}

Tidspunkt for og grad av mobilisering og opptrening må vurderes grundig for å unngå negative konsekvenser av rehabiliteringen (묘). Her drar man veksler på rehabiliteringstradisjonen innenfor generell nevrologi. Videre utredning og etiologisk avklaring går imidlertid i andre retninger enn generell nevrologi og inkluderer bl.a. hypertensjon, diabetes mellitus, hyperlipidemi, atrieflimmer og andre hjertesykdommer. Spesielt hos yngre pasienter finnes et høyt antall andre risikofaktorer og etiologiske 
differensialdiagnoser. Valg av sekundærprofylaktisk behandling blir dermed tilsvarende komplisert $(19, \underline{20})$. Er generell nevrologi et godt nok grunnlag for adekvat håndtering av indremedisinske problemstillinger og sjeldne vaskulære sykdommer?

\section{Poliklinikken}

I forebyggende behandling og i oppfølgingen etter et hjerneslag har nevrologene oppgaver både innenfor kardiovaskulær og nevrovaskulær medisin. Pasienter med subklinisk aterosklerose eller vaskulær kognitiv svikt, med gjennomgått transitorisk iskemisk attakk (TIA) eller tilfeldig oppdagede "stumme infarkter» på CT eller MR, krever tilsvarende

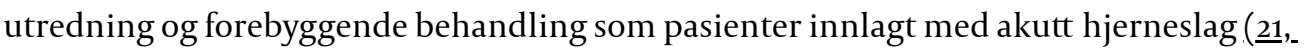
22). Polikliniske problemstillinger er langt på vei de samme som skissert under slagovervåking, nevrovaskulært laboratorium og slagenhet. Generell nevrologi uten vaskulær spesialkompetanse synes heller ikke i poliklinisk sammenheng å være et godt nok tilbud til slagpasientene.

\section{Kvalitet i alle ledd?}

Nasjonal faglig retningslinje for hjerneslag anfører at en slagenhet skal være bemannet med «tverrfaglig spesialopplært personale», at nye akutte behandlingstilbud krever «økt faglig kunnskap» og at slagenheten bør ha "faste overleger med hjerneslag som hovedarbeidsområde» (므). Men det foreligger ingen nasjonale kvalitetskrav til hva «faglig kunnskap» bør være eller hvordan kunnskapen bør erverves. Det foreligger heller ikke nasjonale krav til den diagnostikken, behandlingen og overvåkingen som bør gjennomføres. Hvert sykehus kan selv definere hva som skal tilbys pasientene på deres slagenheter. I Norge eksisterer 46 slagenheter, hvorav 5 er slagsentre som også utfører intraarteriell trombektomi. Disse 46 enhetene har varierende størrelse, varierende bemanning og varierende kunnskap - uten overordnede nasjonale krav.

\section{"Det foreligger ingen nasjonale kvalitetskrav til hva 'faglig kunnskap' bør vcere eller hvordan kunnskapen bør erverves»}

WHO International Statistical Classification of Diseases and Related Health Problems (ICD) omklassifiserte i 2017 hjerneslag fra å være en blodåresykdom (ICD-10) til å være en nevrologisk sykdom (ICD-11) (23,24.). For nevrologien er dette en utfordring. Subspesialisering i vaskulær nevrologi ble etablert i USA allerede i 2003 (25-27.). I flere

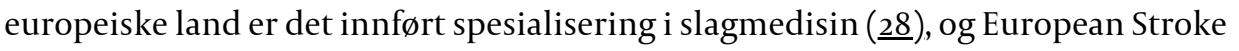
Organisation (ESO) har i flere år tilbudt et masterstudium i stroke medicine (29.). Kompetansekravene i vaskulær nevrologi i Norge er til sammenlikning svært begrenset: Ett kurs i hjernens blod- og væskesirkulasjon, 50 ultralydundersøkelser av halsarterier, ti trombolysebehandlinger og ellers "god kunnskap om» det meste (30). Slagpasienten trenger noe mer enn dette i møte med nevrologien.

For å imøtekomme behovet for et spesialisert pasienttilbud har de fleste nevrologiske avdelinger opprettet egne seksjoner for hjerneslag med slagenhet og vaskulær poliklinikk. Nevrovaskulære laboratorier er under utvikling. Oslo universitetssykehus og Akershus universitetssykehus har fullt ut tatt konsekvensen av at vaskulær nevrologi krever annen kunnskap enn hva generell nevrologi forutsetter og har etablert egne vaktteam for hjerneslag.

Vaskulær nevrologi er grunnleggende annerledes enn generell nevrologi og fremstår i praksis som et eget akuttmedisinsk fagfelt. Det vil være faglig riktig å innføre formalisert kompetanse og en definert ramme for utdanning i vaskulær nevrologi. 


\section{LITTERATUR}

1. Folkehelseinstituttet. Forekomst av hjerte- og karsykdommer i 2020.

https://www.fhi.no/hn/helseregistre-og-registre/hjertekar/forekomst-av-hjerte--og-karsykdommer-i2020/ Lest 1.10.2021.

2. Helsedirektoratet. Nasjonal faglig retningslinje for hjerneslag. https://www.helsedirektoratet.no/tema/hjerneslag Lest 19.7.2021.

3. Stinear CM, Lang CE, Zeiler S et al. Advances and challenges in stroke rehabilitation. Lancet Neurol 2020; 19:348-6o. [PubMed][CrossRef]

4. Campbell BCV, Khatri P. Stroke. Lancet 2020;396: 129-42. [PubMed][CrossRef]

5. Meretoja A, Keshtkaran M, Tatlisumak T et al. Endovascular therapy for ischemic stroke: Save a minute-save a week. Neurology 2017; 88: 2123-7. [PubMed][CrossRef]

6. Moulin S, Leys D. Stroke mimics and chameleons. Curr Opin Neurol 2019;32: 54-9. [PubMed] [CrossRef]

7. Emberson J, Lees KR, Lyden P et al. Effect of treatment delay, age, and stroke severity on the effects of intravenous thrombolysis with alteplase for acute ischaemic stroke: a meta-analysis of individual patient data from randomised trials. Lancet 2014;384: 1929-35. [PubMed][CrossRef]

8. Davis SM, Campbell BCV, Donnan GA. Endovascular thrombectomy and stroke physicians equity, access, and standards. Stroke 2017; 48: 2042-4. [PubMed][CrossRef]

9. Cordonnier C, Demchuk A, Ziai W et al. Intracerebral haemorrhage: current approaches to acute management. Lancet 2018; 392: 1257-68. [PubMed][CrossRef]

10. Fassbender K, Walter S, Grunwald IQ et al. Prehospital stroke management in the thrombectomy era. Lancet Neurol 2020; 19: 601-10. [PubMed][CrossRef]

11. Phipps MS, Cronin CA. Management of acute ischemic stroke. BMJ 2020;368: 16983. [PubMed] [CrossRef]

12. Smith M, Reddy U, Robba $C$ et al. Acute ischaemic stroke: challenges for the intensivist. Intensive Care Med 2019; 45: 1177-89. [PubMed][CrossRef]

13. Bonow RH, Young CC, Bass DI et al. Transcranial Doppler ultrasonography in neurological surgery and neurocritical care. Neurosurg Focus 2019; 47: E2. [PubMed][CrossRef]

14. Thomassen L, Fromm A, Aarli S et al. Transkranial ultralydovervåking ved hjerneslag. Tidsskr Nor Legeforen 2021; 141. doi: 10.4045/tidsskr.21.0180. [PubMed][CrossRef]

15. Nedelmann M, Stolz E, Gerriets T et al. Consensus recommendations for transcranial color-coded duplex sonography for the assessment of intracranial arteries in clinical trials on acute stroke. Stroke 2009; 40:3238-44. [PubMed][CrossRef]

16. Robba C, Poole D, Citerio G et al. Brain ultrasonography consensus on skill recommendations and competence levels within the critical care setting. Neurocrit Care 2020;32: 502-11. [PubMed] [CrossRef]

17. Langhorne P, Wu O, Rodgers H et al. A Very Early Rehabilitation Trial after stroke (AVERT): a Phase III, multicentre, randomised controlled trial. Health Technol Assess 2017; 21:1-120. [PubMed] [CrossRef]

18. Putaala J. Ischemic stroke in the young: Current perspectives on incidence, risk factors, and cardiovascular prognosis. Eur Stroke J 2016; 1: 28-40. [PubMed][CrossRef]

19. Ekker MS, Boot EM, Singhal AB et al. Epidemiology, aetiology, and management of ischaemic stroke in young adults. Lancet Neurol 2018; 17: 790-801. [PubMed][CrossRef]

20. Webster F, Saposnik G, Kapral MK et al. Organized outpatient care: stroke prevention clinic referrals are associated with reduced mortality after transient ischemic attack and ischemic stroke. Stroke 2011; 42:3176-82. [PubMed][CrossRef]

21. Gupta A, Giambrone AE, Gialdini G et al. Silent brain infarction and risk of future stroke a systematic review and meta-analysis. Stroke 2016; 47: 719-25. [PubMed][CrossRef]

22. Shakir R, Davis S, Norrving B et al. Revising the ICD: stroke is a brain disease. Lancet 2016; 388 : 2475-6. [PubMed][CrossRef]

23. Shakir R, Norrving B. Stroke in ICD-11: the end of a long exile. Lancet 2017;389: 2373. [PubMed] [CrossRef]

24. Adams HP, Kenton EJ, Scheiber SC et al. Vascular neurology: a new neurologic subspecialty. Neurology 2004; 63: 774-6. [PubMed][CrossRef] 
25. Hodgson TS, Brorson JR, Ardelt AA et al. Accrediting neurology fellowships accelerates subspecialization. Front Neurol 2013; 4: 94. [PubMed][CrossRef]

26. Adams HP, Biller J. Future of subspecialty training in vascular neurology. Stroke $2014 ; 45: 3730-3$. [PubMed][CrossRef]

27. Meretoja A, Acciarresi M, Akinyemi RO et al. Stroke doctors: Who are we? A World Stroke Organization survey. Int J Stroke 2017; 12: 858-68. [PubMed][CrossRef]

28. European Stroke Organisation. https://eso-stroke.org/resources/european-master-programme-instroke-medicine/ Lest 16.6.2021.

29. Helsedirektoratet. Spesialistutdanning for leger: Nevrologi.

https://www.helsedirektoratet.no/tema/autorisasjon-og-spesialistutdanning/spesialistutdanning-forleger/nevrologi Lest 25.5.2021.

30. Grotta JC, Lyden P, Brott T. Rethinking training and distribution of vascular neurology interventionists in the era of thrombectomy. Stroke 2017; 48: 2313-7. [PubMed][CrossRef]

Publisert: 22. november 2021. Tidsskr Nor Legeforen. DOI: 10.4045/tidsskr.21.0618

Mottatt 31.8.2021, første revisjon innsendt 8.10.2021, godkjent 18.10.2021.

(C) Tidsskrift for Den norske legeforening 2023. Lastet ned fra tidsskriftet.no 26. april 2023. 